WIAS Discussion Paper No.2016-005

Climate, crime, and suicide: Empirical evidence from Japan

February 13, 2017

Ryo Takahashi

Institute for Advanced Study, Waseda University

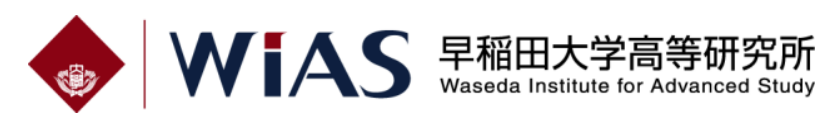

1-6-1 Nishiwaseda, Shinjuku-ku, Tokyo 169-8050, Japan

Te1: 03-5286-2460 ; Fax: 03-5286-2470 


\title{
Climate, crime, and suicide: Empirical evidence from Japan
}

\author{
Ryo Takahashi
}

Waseda University

\begin{abstract}
The relationship between climate change and violent behavior has been well documented in previous studies. Violence has two dimensions: outward violence (i.e., crime) and inward violence (i.e., suicide). To our knowledge, rigorous empirical studies have not been performed to investigate how climate change affects both criminal and suicidal behavior. This study aims to estimate the effects of climate change on crime and suicide in Japan by using prefecture-level monthly panel data on climate, crime, and suicide between 2009 and 2015. Even after controlling for prefecture, yearly, and monthly effects, we found that many climate factors affected both crime and suicide in Japan. In particular, more aggressive behavior and an increased number of suicides were observed when the average temperature increased. Furthermore, we predicted how changes in the climate of Japan will affect future patterns of criminal and suicidal behavior based on two climate change scenarios.
\end{abstract}

Keywords: climate change; crime; suicide; violence

Correspondence Author: Ryo Takahashi, Email: inter.takahashi@gmail.com 


\section{Introduction}

Climate change is a serious global problem, and although a number of environmental conservation efforts have been implemented (Takahashi and Todo 2012, Takahashi and Todo 2013, Takahashi and Todo 2014, Otsuka et al. 2015, Takahashi 2016), many studies have shown that the problem has continued to progress (Bellard et al. 2012, Hansen et al. 2012, Rogelj et al. 2013, Kirchner et al. 2016). Additionally, the Intergovernmental Panel on Climate Change (IPCC) reported in 2014 that the global mean surface temperature may increase by 0.3 to 0.7 degrees Celsius from 2016 to 2035 relative to the temperatures recorded from 1986 to 2005.

The relationship between high temperatures and aggressive behavior has been investigated for more than three decades. For example, Kenrick and MacFarlane (1986) conducted an experiment in Arizona, USA, and found that people become more aggressive with regard to car horn honking in a high-temperature environment. Reifman et al. (1991) used interesting datasets, such as the archival data of major league baseball games, to examine the heat-aggression relationship, and their results showed a positive relationship between temperature and the number of injured batters per game. They concluded that higher temperatures led pitchers to become more aggressive in their pitching to batters. Vrij et al. (1994) conducted an experiment in Holland and found that Dutch police officers in high temperature conditions became more aggressive and shot people more often during shooting exercises.

Studies have also focused on how high temperatures influence actual violence, such as crimes and conflicts (DeFronzo 1984, Anderson 1987, Anderson et al. 2000, Anderson 2001). Ranson (2014) used monthly panel data collected over 30 years to examine the relationship between temperature and criminal behavior in the United States, and the results indicated that climate change will likely cause additional criminal cases, such as murder, rape, assault, robbery, burglary, larceny, and vehicle theft. Other studies conducted in the United States also confirmed that annual temperatures are positively associated with violent crimes (Rotton and Cohn 2003, Jacob et al. 2007). Moreover, Burke et al. (2009) focused on the incidence of internal armed conflict in Africa and estimated that rising temperatures caused by climate change led to a 54 percent increase in the incidence of conflict and caused nearly 400,000 battle deaths. The linkage between civil war and temperature was also shown in a study by Hsiang et al. (2013). 
Although the above studies focused on the relationship between heat and outward acts of violence, violence has an additional dimension: inward violence, such as suicide (Zhang et al. 2011). Several studies have been conducted to examine the effect of climate on suicide. Preti (1998) investigated the influence of climate on suicidal behavior in 17 cities in Italy and found that certain climate factors, such as humidity, precipitation, and sunlight exposure, had a significant impact on suicide rates. Lee et al. (2006) found that ambient temperature is positively associated with suicide rates in Taiwan, and Ruuhela et al. (2009) analyzed data from 1971 to 2003 and found that the average temperature is a factor that triggers suicidal behavior in Finland. These studies used simple regression procedures to examine the relationship between climate and suicide. However, the results of such simple regression analyses are likely biased by unobserved factors (Imbens and Wooldridge 2009). Hence, rigorous empirical research is needed.

Another shortcoming of the available literature is that most previous studies primarily focused on one dimension of violence (i.e., crime or suicide), whereas less attention has been devoted to investigating how climate factors affect both outward and inward violence.

Therefore, this study aims to investigate the effects of climate factors, particularly the average temperature, on crime and suicide cases. Based on the estimation results, the study will further discuss how climate change will affect the number of crimes and suicide deaths in 2100 using climate change scenarios established by the IPCC, with Japan selected as the case study. One advantage of selecting Japan is data availability because monthly climate, crime, and suicide data are available at the subnational jurisdiction level, or prefecture level. This study covers the period from 2009 to 2015, and the estimation assesses variations over time and across the 47 prefectures of Japan.

This study makes three main contributions. First, empirical studies that concurrently examine how climate factors affect two types of violence are not available. Using extensive data from Japan, this study provides rigorous empirical evidence regarding the linkage between climate and violent crime and suicide.

Second, this study provides empirical insights into whether low-crime secure regions will be influenced by climate change. Many studies have shown that the crime rate in Japan is fairly low compared to those in other countries (Leonardsen 2004, Vazsonyi et al. 2004). According to Komiya 
(1999), the Japanese social structure leads to low crime rates. However, it is not clear whether climate factors affect violent acts, even under Japan's social norms. As mentioned, Ranson (2014) conducted a detailed analysis in the United States, which is characterized as a country with high crime rates. Thus, the analysis performed here can provide new insights into the relationship between climate and violent behavior in the low-crime country of Japan.

Third, the findings of this study may have important policymaking implications. Since the late 1990s, the number of suicides has drastically increased in Japan, and more than 30,000 people have died from suicide each year (Chen et al. 2012). Based on data published by the Japanese Ministry of Health, Labour and Welfare, suicide ranked eighth among the cause-of-death categories in 2014. Death statistics based on age group show that suicide was the number one cause of death for seven groups of males aged 10-44 and four groups of females aged 15-34. Because suicide is a critical issue in Japan, many scholars have focused on the determinants of suicidal behavior (Aihara and Iki 2003, Chen et al. 2009, Matsubayashi et al. 2013), and the Japanese legislature has enacted policies to tackle this issue ("Basic Law of Suicide Prevention"). However, none of these studies or policies has focused on climate change with regard to preventing aggressive suicide acts in Japan. This study has the potential to provide useful information regarding the linkage between climate and suicidal behavior, which will potentially help reduce suicide cases.

\section{Methodology and data}

\subsection{Data}

In this study, a seven-year monthly panel dataset on the 47 prefectures of Japan from January 2009 to September 2015 was established. The total number of observations was 3,807 prefecture months. The average size of the 47 prefectures was $8,042 \mathrm{~km}^{2}$ (Table 1), and the difference in size between the largest prefecture (i.e., Hokkaido $83,424 \mathrm{~km}^{2}$ ) and the smallest prefecture (i.e., Kagawa $1,877 \mathrm{~km}^{2}$ ) was $81,547 \mathrm{~km}^{2}$.

Data on the climate factors were obtained from the Japan Meteorological Agency, and the following climate factors were collected from the observatories located in each prefectural capital: the average temperature (degrees Celsius) and the average total precipitation $(100 \mathrm{~mm})^{\mathrm{i}}$. Crime data were 
obtained from the Statistics Bureau under the Ministry of Internal Affairs and Communications. Following Ranson (2014), this study focuses on nine major crimes: murder, assault, arson, rape, sexual assault, abduction, robbery, burglary, and vehicle theft. The suicide statistics were obtained from the Cabinet Office, Government of Japan. To estimate the crime and suicide cases per 100,000 persons, population statistics from the Statistics Bureau were used. However, because monthly prefectural population data were not available, the population in October for each prefecture was used to estimate the crime and suicide cases per 100,000 persons for each year.

The summary statistics are presented in Table 1. The climate characteristics of Japan are associated with an average temperature of approximately 16 degrees Celsius and average monthly precipitation of $146 \mathrm{~mm}$. The average monthly crime cases show that most are below 1 case per 100,000 persons except for assault and burglary. Compared to the crime statistics in the United States presented in Ranson (2014), the crime cases per 100,000 in Japan are low, which indicates that Japan is a low-crime country as expected.

In the case of the average monthly suicide case, the total average suicide case, including males and females, is 1.9 cases per 100,000 persons. However, the suicide cases between males and females are quite different. The average male suicide case is approximately 2.8 cases per 100,000 persons, while the female suicide case is 1.1 events, which is less than half of the male case.

Figure 1 shows the change in violent crime and suicide cases per 100,000 persons between January 2009 and September 2015 in Japan. In this study, violent crimes are defined as murder, assault, arson, rape, and sexual assault. The black dashed line in Figure 1 indicates the violent crime case per 100,000 persons, whereas the suicide case is illustrated as a gray line. The horizontal axis in Figure 1 indicates the four seasons in each Japanese year: the spring season from March to May, summer season from June to August, autumn season from September to November, and winter season from December to February.

The figure shows that the violent crime case exhibits strong seasonality. During the spring period, the violent crime case drastically increases and reaches a peak in summer. In winter, the crime case rapidly drops. For suicide cases, although the degree of seasonal variation is modest, an increase in the suicide case in spring is observed. 
A sharp increase in the suicide case occurred at the end of spring 2011, which was likely because of the great east Japan earthquake that occurred on March 11, 2011. An unprecedented magnitude 9.0 earthquake hit northeastern Japan in an area called the Tohoku region. Because devastating natural disasters are known to cause psychological distress, including posttraumatic stress disorder (PTSD), depression, and suicidality (Wu et al. 2006, Suzuki et al. 2011), the suicide case during this period may have increased.

Map (a) in Figure 2 shows the average annual temperature at the prefecture level. The average temperature is lower in northern Japan, and the temperature increases from the average of 12.5 degrees Celsius in the north to 17.5 degrees Celsius in the southern region. Maps (b) and (c) show the average annual cases of violent crime and theft per 100,000 persons, respectively, with theft including robbery and burglary. As the figure shows, the annual violent crime case is relatively high in the middle-west part of Japan (i.e., Osaka Prefecture), whereas thefts are more common in the central and east-central regions. Moreover, the average annual suicide case per 100,000 persons shown in map (d) indicates that suicide cases are relatively high in the northern and east-central parts of Japan. These four maps clearly show that an obvious cross-sectional relationship does not exist between temperature and any type of violent behavior.

\subsection{Hypothesis and methods}

The previous studies repeatedly found that individuals are more likely to exhibit violent behavior toward others if ambient temperatures are high. Since violence has two dimensions, this study primarily focuses on the relationship between the temperature and violence. Specifically, we hypothesize that high temperatures induce an increase in both crime and suicide cases in Japan. To test the above hypothesis and examine the association between climate and violent acts, we use a prefecture fixed-effect model ${ }^{\text {ii }}$. Our model can be defined as follows:

$$
V_{\text {imt }}=\beta_{1} \text { Climate }_{\text {imt }}+\mu_{m}+\tau_{t}+\rho_{i}+\varepsilon_{\text {imt }},
$$

where $V_{i m t}$ denotes the crime or suicide case per 100,000 persons in prefecture $i$ in month $m$ during 
year $t$, Climate $_{i m t}$ represents a vector of climate characteristics for prefecture $i$ in month $m$ during year $t$, and $\rho_{i}$ represents prefecture-specific fixed effects. In this study, the average temperature and average total precipitation are included as climate characteristics. Equation 1 also contains a full set of year dummies, $\tau_{t}$, as well as a full set of month dummies, $\mu_{m}$. Additionally, $\varepsilon_{i m t}$ is an error term.

The prefecture-specific fixed effects capture the effects of time-invariant unobserved factors that could be related to crime and suicide cases, and these factors include the culture and norms of each prefecture and stable socioeconomic conditions. Additionally, although the prefectural area differs among prefectures (Table 1), any impact associated with prefecture size is accounted for by the inclusion of prefecture-specific fixed effects.

The year dummies capture the effects of economic fluctuations and any other major events in Japan in a particular year. Note that the significant impact caused by the great east Japan earthquake in 2011 is accounted for by the inclusion of year dummies. Month dummies are also included in Equation 1 to control the seasonal patterns observed in Figure 1.

\section{Results}

\subsection{Empirical results}

The regression results from estimating Equation 1 are presented in Table 2. Despite controlling for the effects of the prefecture, year, and month, we found that the average temperature had a significantly positive effect on many types of crime, such as murder, assault, sexual assault, robbery, burglary, and vehicle theft. The coefficients between average temperature and crime cases vary depending on the type of crime, e.g., the effects on assault and burglary are higher than those associated with other crimes. However, it does not mean that these two crimes are more sensitive to temperature than are other crimes. These coefficients are higher simply because the crime cases of assault and burglary are higher than other crime cases, as shown in Table 1. Overall, these results clearly indicate that high temperatures stimulate aggressive behavior in Japan, which is consistent with the findings of previous studies from the United States (Rotton and Cohn 2003, Jacob et al. 2007, Ranson 2014) ${ }^{\mathrm{iii}}$.

By contrast, the average total precipitation negatively affected the assault and burglary cases, 
which is consistent with the findings of Jacob et al. (2007) in the United States. One possible explanation is that the likelihood of individuals staying home on rainy days may be higher than that on sunny days, thereby reducing the possibility of assault and break-in crimes. A similar explanation was given by Rotton and Cohn (2003).

Next, to identify the linkage between climate and suicide, we conduct the same analysis using the suicide case per 100,000 persons as the outcome variable, and the results are reported in Table 3 . The estimation results using the total suicide case in column 1 indicate that the number of suicides tends to increase with average temperature, which is consistent with the results of previous studies (Lee et al. 2006, Page et al. 2007, Likhvar et al. 2011). This result provides important and interesting insights. As map (d) in Figure 2 clearly illustrates, the mean annual suicide cases are relatively high in the northeastern regions (Tohoku region) where the average temperature is relatively low compare to those in other regions. These results indicate that the high suicide cases in Tohoku region are due to non-climate factors, such as economic conditions, and, in general, an increase in the average temperature affects the suicide behaviors of the residents in the Tohoku region.

The results of male and female suicide cases per 100,000 persons are presented in columns 2 and 3 , respectively. The linkage between ambient temperatures and suicide cases is observed in both male and female suicide cases, while its magnitude is larger for male suicide cases. Although these results are consistent with the findings of Lee et al. (2006), the reasons why high temperatures induce more male suicides than female suicides are not clear. Therefore, further study is needed to investigate how high temperatures specifically increase male suicide cases.

Even after controlling for prefecture-specific effects as well as year and month effects, we still found that the crime and suicide cases in Japan were strongly influenced by many climate factors. In particular, our estimation results indicated that the average temperature is a major driver of many types of criminal activities and suicidal acts ${ }^{\mathrm{i}}$.

\subsection{Climate change scenario in 2100 and violent incidents in Japan}

The results of this study raise an important question as to how crime and suicide cases per 100,000 persons in Japan will be affected under different climate change scenarios. To answer this 
question, the regression estimates from Equation 1 were combined with the climate change scenarios simulated by the Ministry of the Environment for the time period from 2080 to 2100 . These scenarios are based on the IPCC's RCP2.6 and RCP8.5 scenarios.

The Ministry of the Environment in Japan reported in 2014 that the average temperature in Japan will rise by approximately 1.1 degrees Celsius according to the RCP2.6 scenario or 4.4 degrees Celsius according to the RCP8.5 scenario compared to the baseline temperature between 1983 and 2004. Both scenarios predict that the average annual precipitation will not significantly change. Therefore, this study focused on the average temperature predictions in Japan in 2100. Furthermore, because the average temperature only affects the crime cases per 100,000 persons of six crimes, including murder, assault, sexual assault, robbery, burglary, and vehicle theft, the methods by which climate-induced changes in average temperature increase the number of these crimes and suicides in Japan were simulated relative to the number that would occur if temperatures remained at the 2009-2014 average. The number of crimes and suicides in 2015 were excluded because of the lack of data between October and December of that year.

The mean annual number of crimes and suicides in Japan is listed in column 1 of Table 4, whereas the predicted impacts, such as the additional number of crime and suicide cases under the RCP2.6 and RCP8.5 scenarios, are presented in columns 2 and 3, respectively. Between 2009 and 2014, more than 1,000 cases of murder were observed annually in Japan. Based on the estimation results in Table 2, a rise in temperature of one degree Celsius increased the murder case per 100,000 persons of the country by 0.001 . Because Japan has a population of approximately 127 million, an increase of 0.001 in the murder case per 100,000 persons translates to 15 people per year. If the assumption of the RCP2.6 scenario is true, our results suggest that the annual average number of murder victims in 2100 will increase by 17 compared to the average between 2009 and 2014 in Japan. In the worst-case scenario (RCP8.5), 67 additional murder cases will occur due to climate change in 2100. Although this may seem like a small difference, these results represent a $2-7$ percent increase in murder compared to the baseline number of murder cases.

Moreover, in 2100, there will be an additional 252-1,006 assaults, 117-469 sexual assaults, 17-67 robberies, 1,324-5,297 burglaries, and 101-402 vehicle theft cases because of climate change. 
Compared to the average number of crimes between 2009 and 2014, these results indicate a 1-4 percent increase in assault, a 2-7 percent increase in sexual assault, a 1-2 percent increase in robbery, a 1-4 percent increase in burglary, and a 1-2 percent increase in cases of vehicle theft.

Although it is difficult to compare these results to the predictions presented in previous studies, our estimation results show that the number of suicide deaths also increased due to climate change. Although approximately 28 thousand suicide deaths occurred on average each year between 2009 and 2014 , the annual number of suicides will increase by $369-1,475$ in 2100 , representing a $1-5$ percent increase.

\section{Conclusions and Discussion}

This study provided systematic evidence of the relationship between climate factors and violent activities, such as crime and suicide, in Japan by using extensive climate, crime, and suicide data from 2009 to 2015. Even after controlling for prefecture, year, and month effects, we found that many climate factors affected the crime and suicide cases per 100,000 persons in Japan. In particular, people became more aggressive and committed suicide at a greater frequency when the average temperature increased. However, as Hsiang et al. (2013) indicated, the physiological mechanism linking temperature to aggressive behavior remains unknown, and, thus, further physiological or psychological investigations are needed.

Furthermore, we predicted how changes in the Japanese climate will affect future patterns of criminal and suicidal behavior based on two IPCC climate change scenarios: RCP2.6 and RCP8.5. The predicted results suggest that climate change will have substantial effects on the prevalence of crime and suicide in Japan.

These findings have important policymaking implications. Suicide is a serious social issue in present-day Japan, and many policies have been implemented to reduce suicide cases. For example, the "Basic Law of Suicide Prevention" was enacted in 2006, and the Cabinet Office of Japan outlined comprehensive guidelines for suicide prevention in 2007. Additionally, major railway operators in Japan installed blue light-emitting-diode (LED) lamps on railway platforms and at railway crossings as a method of preventing suicides, and these measures had a significant impact on decreasing the 
number of suicides (Matsubayashi et al. 2013).

Moreover, although Japan still has a low crime case per 100,000 (Halicioglu et al. 2012), the Japanese public has lost confidence in their country's safety and is increasingly fearful of crime (Hamai and Ellis 2006). To sustain the low crime rate in Japan, the "Ministerial Meeting for Anti-Crime Measures" has been held twice each year since 2003. In addition, a number of academic discussions regarding approaches to crime prevention have taken place. For example, scholars have suggested utilizing the local community to prevent and mitigate crime and the fear of crime (Hino and Schneider 2013), whereas others point to the possibility of preventing crime using a web-based system for gathering and sharing crime information (Goto et al. 2006).

Although these policies and discussions are essential to preventing crime and suicide, they do not consider the effects of climate on crime and suicide cases. What we found in this study is that mitigating global climate change can improve crime and suicide prevention efforts. Hence, to reduce the risks of criminal and suicidal acts in Japan, it is important to strengthen the relationships between various institutions, such as the Cabinet Office of Japan, the Metropolitan Police Department, and the Ministry of Environment, to address climate change. 


\section{References}

Aihara, H and M Iki (2003). An ecological study of the relations between the recent high suicide rates and economic and demographic factors in Japan. Journal of Epidemiology, 13, 56-61.

Anderson, CA (1987). Temperature and aggression: Effects on quarterly, yearly, and city rates of violent and nonviolent crime. Journal of Personality and Social Psychology, 52, 1161.

Anderson, CA (2001). Heat and violence. Current Directions in Psychological Science, 10, 33-38.

Anderson, CA, KB Anderson, N Dorr, KM DeNeve and M Flanagan (2000). Temperature and aggression. Advances in Experimental Social Psychology, 32, 63-133.

Bellard, C, C Bertelsmeier, P Leadley, W Thuiller and F Courchamp (2012). Impacts of climate change on the future of biodiversity. Ecology Letters, 15, 365-377.

Burke, MB, E Miguel, S Satyanath, JA Dykema and DB Lobell (2009). Warming increases the risk of civil war in Africa. Proceedings of the National Academy of Sciences, 106, 20670-20674.

Chen, J, YJ Choi, K Mori, Y Sawada and S Sugano (2012). Socio-economic studies on suicide: A survey. Journal of Economic Surveys, 26, 271-306.

Chen, J, YJ Choi and Y Sawada (2009). How is suicide different in Japan? Japan and the World Economy, 21, 140-150.

DeFronzo, JW (1984). Climate and crime tests of an FBI assumption. Environment and Behavior, 16, $185-210$.

Goto, M, A Hattori, T Yasuda and S Yokoi (2006). A web-based system for gathering and sharing experience and knowledge information in local crime prevention. In Knowledge-Based Intelligent Information and Engineering Systems, Bournemouth, UK, October 9-11.

Halicioglu, F, AR Andrés and E Yamamura (2012). Modeling crime in Japan. Economic Modelling, 29, $1640-1645$

Hamai, K and T Ellis (2006). Crime and criminal justice in modern Japan: From re-integrative shaming to popular punitivism. International Journal of the Sociology of Law, 34, 157-178.

Hansen, J, M Sato and R Ruedy (2012). Perception of climate change. Proceedings of the National Academy of Sciences, 109, E2415-E2423.

Hino, K and RH Schneider (2013). Planning for crime prevention in Japan. Built Environment, 39, 
$114-139$.

Hsiang, SM, M Burke and E Miguel (2013). Quantifying the influence of climate on human conflict. Science, 341, 1235367.

Imbens, GM and JM Wooldridge (2009). Recent developments in the econometrics of program evaluation. Journal of Economic Literature, 47, 5-86.

Jacob, B, L Lefgren and E Moretti (2007). The dynamics of criminal behavior evidence from weather shocks. Journal of Human Resources, 42, 489-527.

Kenrick, DT and SW MacFarlane (1986). Ambient temperature and horn honking a field study of the heat/aggression relationship. Environment and Behavior, 18, 179-191.

Kirchner, M, M Schönhart and E Schmid (2016). Spatial impacts of the CAP post-2013 and climate change scenarios on agricultural intensification and environment in Austria. Ecological Economics, 123, 35-56.

Komiya, N (1999). A cultural study of the low crime rate in Japan. British Journal of Criminology, 39, 369-390.

Lee, H-C, H-C Lin, S-Y Tsai, C-Y Li, C-C Chen and C-C Huang (2006). Suicide rates and the association with climate: A population-based study. Journal of Affective Disorders, 92, 221-226.

Leonardsen, D (2004). Japan as a Low-Crime Nation. Basingstoke, UK: Palgrave Macmillan.

Likhvar, V, Y Honda and M Ono (2011). Relation between temperature and suicide mortality in Japan in the presence of other confounding factors using time-series analysis with a semiparametric approach. Environmental Health and Preventive Medicine, 16, 36-43.

Matsubayashi, T, Y Sawada and M Ueda (2013). Does the installation of blue lights on train platforms prevent suicide? A before-and-after observational study from Japan. Journal of Affective Disorders, 147, 385-388.

Matsubayashi, T, Y Sawada and M Ueda (2013). Natural disasters and suicide: Evidence from Japan. Social Science \& Medicine, 82, 126-133.

Otsuka, K, R Takahashi and R Pokharel (2015). In search of optimum institutions for forest management. Journal of Sustainable Forestry, 34, 300-314. 
Page, LA, S Hajat and RS Kovats (2007). Relationship between daily suicide counts and temperature in England and Wales. The British Journal of Psychiatry, 191, 106-112.

Preti, A (1998). The influence of climate on suicidal behaviour in Italy. Psychiatry Research, 78, 9-19.

Ranson, M (2014). Crime, weather, and climate change. Journal of Environmental Economics and Management, 67, 274-302.

Reifman, A, R Larrick and S Fein (1991). Temper and temperature on the diamond: The heat-aggression relationship in major league baseball. Personality and Social Psychology Bulletin, 17, 580-585.

Rogelj, J, DL McCollum, A Reisinger, M Meinshausen and K Riahi (2013). Probabilistic cost estimates for climate change mitigation. Nature, 493, 79-83.

Rotton, J and EG Cohn (2003). Global warming and U.S. crime rates: An application of routine activity theory. Environment and Behavior, 35, 802-825.

Ruuhela, R, L Hiltunen, A Venäläinen, P Pirinen and T Partonen (2009). Climate impact on suicide rates in Finland from 1971 to 2003. International Journal of Biometeorology, 53, 167-175.

Suzuki, Y, A Tsutsumi, M Fukasawa, H Honma, T Someya and Y Kim (2011). Prevalence of mental disorders and suicidal thoughts among community-dwelling elderly adults 3 years after the Niigata-Chuetsu earthquake. Journal of Epidemiology, 21, 144-150.

Takahashi, R (2016). Coffee certification and forest quality: Evidence from a wild coffee forest in Ethiopia. WIAS Working Paper No. 2015-004, Tokyo, Japan.

Takahashi, R and Y Todo (2012). Impact of community-based forest management on forest protection: Evidence from an aid-funded project in Ethiopia. Environmental Management, 50, 396-404.

Takahashi, R and Y Todo (2013). The impact of a shade coffee certification program on forest conservation: A case study from a wild coffee forest in Ethiopia. Journal of Environmental Management, 130, 48-54.

Takahashi, R and Y Todo (2014). The impact of a shade coffee certification program on forest conservation using remote sensing and household data. Environmental Impact Assessment Review, 44, 76-81.

Vazsonyi, AT, JEC Wittekind, LM Belliston and TD Van Loh (2004). Extending the General Theory of 
Crime to "The East:" Low self-control in Japanese late adolescents. Journal of Quantitative Criminology, 20, 189-216.

Vrij, A, J Van der Steen and L Koppelaar (1994). Aggression of police officers as a function of temperature: An experiment with the fire arms training system. Journal of Community \& Applied Social Psychology, 4, 365-370.

Wu, H-C, P Chou, F Huang-Chih Chou, C-Y Su, K-Y Tsai, W-C Ou-Yang, T Tung-Ping Su, S-S Chao, W-J Sun and M-C Chen (2006). Survey of quality of life and related risk factors for a Taiwanese village population 3 years post-earthquake. Australian and New Zealand Journal of Psychiatry, 40, 355-361.

Zhang, J, WF Wieczorek, Y Conwell and XM Tu (2011). Psychological strains and youth suicide in rural China. Social Science \& Medicine, 72, 2003-2010. 
Figure 1: Seasonal trends of violent crime and suicide rates per 100,000 persons between 2009 and 2015

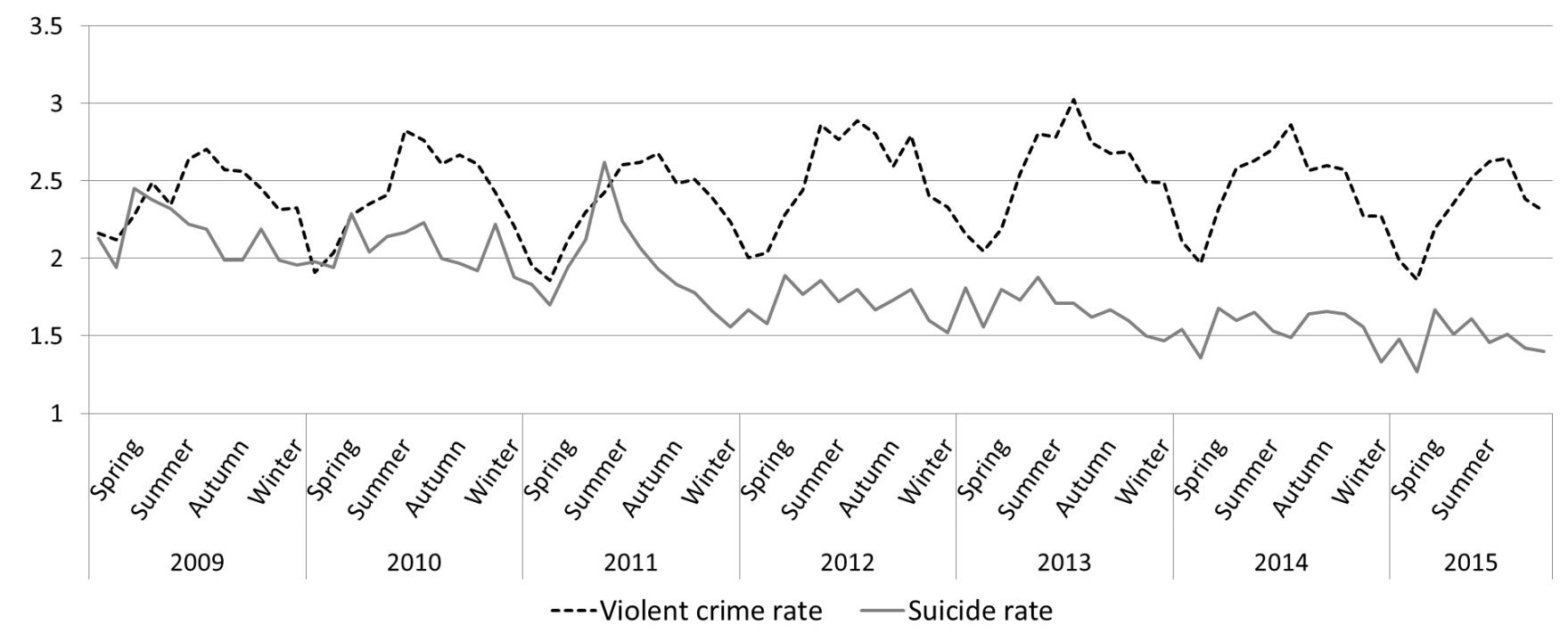


Figure 2: Map of the study region: (a) mean annual average temperature, (b) mean annual violent crime rate per 100,000 persons, (c) mean annual theft rate per 100,000 persons, and (d) mean annual suicide rate per 100,000 persons

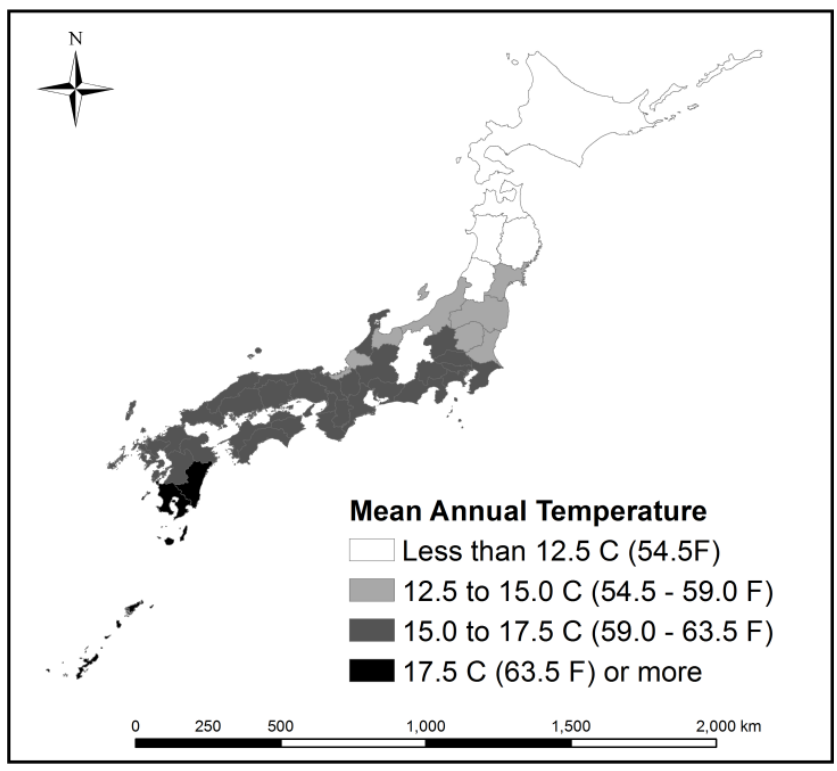

(a)

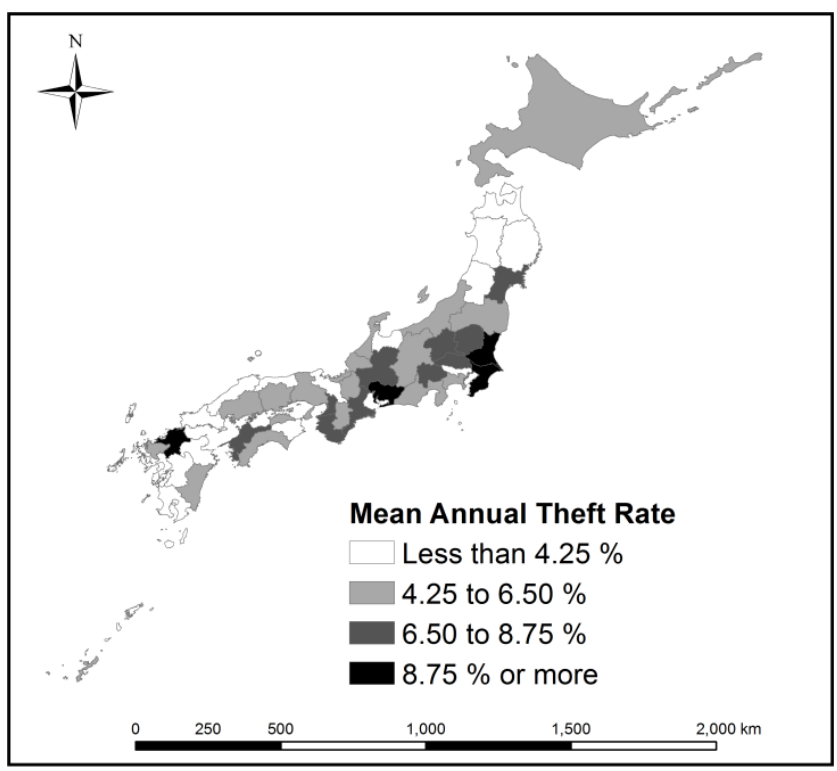

(c)

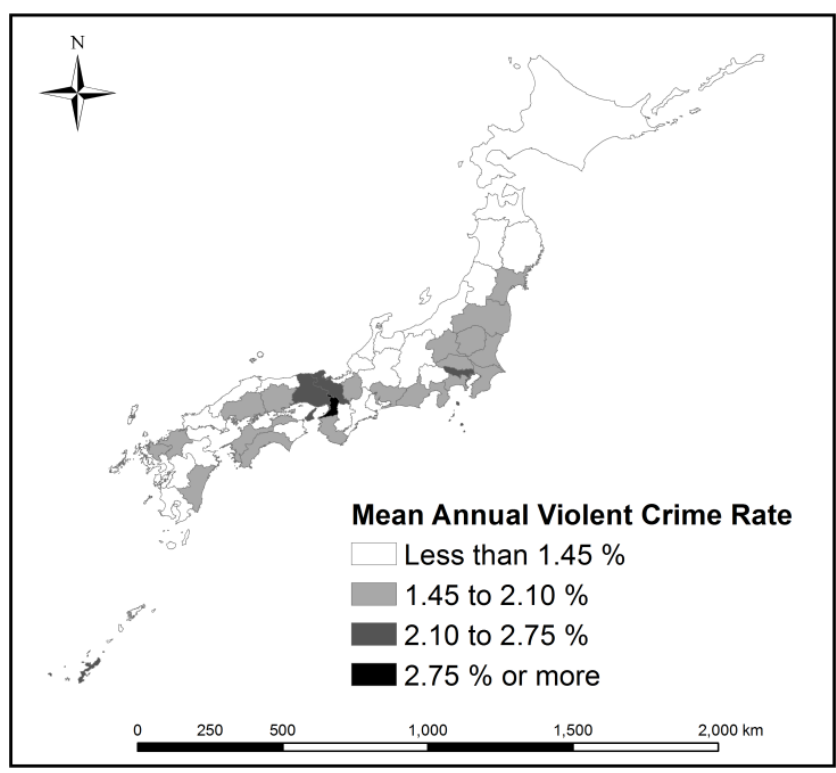

(b)

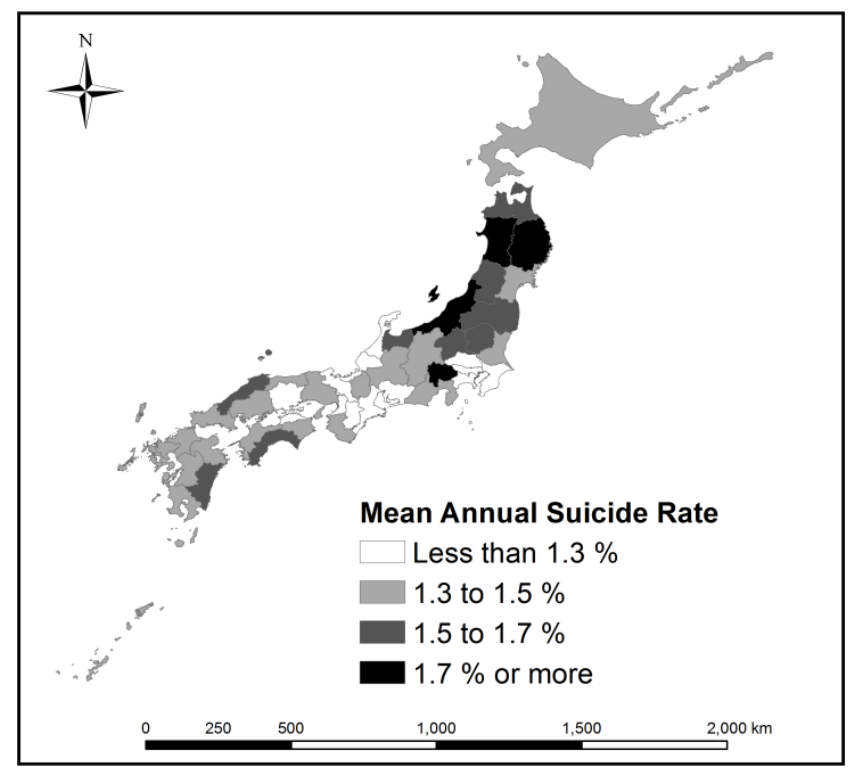

(d) 
Table 1: Summary statistics

\begin{tabular}{|c|c|c|c|c|}
\hline & $\begin{array}{c}\text { Mean } \\
\text { (1) }\end{array}$ & $\begin{array}{c}\text { Standard } \\
\text { deviation } \\
\text { (2) }\end{array}$ & $\begin{array}{l}\text { Min } \\
(3)\end{array}$ & $\begin{array}{c}\text { Max } \\
\text { (4) }\end{array}$ \\
\hline Size of the prefecture $\left(\mathrm{km}^{2}\right)$ & $8,041.96$ & $11,569.79$ & $1,876.73$ & $83,424.22$ \\
\hline \multicolumn{5}{|l|}{ Average climate indicators } \\
\hline Temperature $\left({ }^{\circ} \mathrm{C}\right)$ & 15.61 & 8.48 & -4.70 & 30.50 \\
\hline Total precipitation $(100 \mathrm{~mm})$ & 1.46 & 1.16 & 0 & 15.61 \\
\hline \multicolumn{5}{|l|}{ Average monthly crime rates $(\%)^{*}$} \\
\hline Murder & 0.05 & 0.06 & 0 & 0.50 \\
\hline Assault & 1.12 & 0.84 & 0 & 4.24 \\
\hline Arson & 0.05 & 0.08 & 0 & 0.91 \\
\hline Rape & 0.05 & 0.07 & 0 & 0.51 \\
\hline Sexual assault & 0.28 & 0.28 & 0 & 2.51 \\
\hline Abduction & 0.01 & 0.03 & 0 & 0.38 \\
\hline Robbery & 0.11 & 0.14 & 0 & 0.86 \\
\hline Burglary & 5.22 & 4.18 & 0 & 21.94 \\
\hline Vehicle theft & 0.76 & 1.16 & 0 & 8.63 \\
\hline \multicolumn{5}{|l|}{ Average monthly suicide rates $(\%)^{*}$} \\
\hline Total suicide rate & 1.90 & 0.54 & 0.49 & 4.52 \\
\hline Male suicide rate & 2.77 & 0.89 & 0.53 & 7.07 \\
\hline Female suicide rate & 1.10 & 0.42 & 0 & 3.49 \\
\hline
\end{tabular}

Note: The crime and suicide rates represent the number of monthly crimes/suicides per 100,000 persons 
Table 2: Effects of climate factors on monthly crime rates using the prefecture fixed-effect model

\begin{tabular}{|c|c|c|c|c|c|c|c|c|c|}
\hline & $\begin{array}{c}\text { Murder } \\
\text { (1) }\end{array}$ & $\begin{array}{l}\text { Assault } \\
\text { (2) }\end{array}$ & $\begin{array}{c}\text { Arson } \\
\text { (3) }\end{array}$ & $\begin{array}{c}\text { Rape } \\
(4) \\
\end{array}$ & $\begin{array}{l}\text { Sexual } \\
\text { assault } \\
(5)\end{array}$ & $\begin{array}{c}\text { Abduction } \\
\text { (6) }\end{array}$ & $\begin{array}{c}\text { Robbery } \\
(7)\end{array}$ & $\begin{array}{c}\text { Burglary } \\
(8) \\
\end{array}$ & $\begin{array}{c}\text { Vehicle } \\
\text { theft } \\
(9)\end{array}$ \\
\hline Average temperature $\left({ }^{\circ} \mathrm{C}\right)$ & $\begin{array}{l}0.001 * * * \\
(0.000)\end{array}$ & $\begin{array}{l}0.015^{* * * *} \\
(0.002)\end{array}$ & $\begin{array}{l}-0.000 \\
(0.000)\end{array}$ & $\begin{array}{l}0.000 \\
(0.000)\end{array}$ & $\begin{array}{l}0.007 * * * \\
(0.001)\end{array}$ & $\begin{array}{l}0.000 \\
(0.000)\end{array}$ & $\begin{array}{l}0.001 * * * \\
(0.000)\end{array}$ & $\begin{array}{l}0.079 * * * \\
(0.008)\end{array}$ & $\begin{array}{l}0.006 * * \\
(0.003)\end{array}$ \\
\hline Total precipitation (100 mm) & $\begin{array}{l}0.000 \\
(0.001)\end{array}$ & $\begin{array}{l}-0.016 * * * \\
(0.006)\end{array}$ & $\begin{array}{l}-0.000 \\
(0.001)\end{array}$ & $\begin{array}{l}-0.000 \\
(0.001)\end{array}$ & $\begin{array}{l}0.001 \\
(0.003)\end{array}$ & $\begin{array}{l}0.001 \\
(0.000)\end{array}$ & $\begin{array}{l}0.000 \\
(0.002)\end{array}$ & $\begin{array}{l}-0.071 * * \\
(0.029)\end{array}$ & $\begin{array}{l}-0.001 \\
(0.010)\end{array}$ \\
\hline Constant & $\begin{array}{l}0.060 * * * \\
(0.004)\end{array}$ & $\begin{array}{l}1.263 * * * \\
(0.025)\end{array}$ & $\begin{array}{l}0.091 * * * \\
(0.005)\end{array}$ & $\begin{array}{l}0.066^{* * *} \\
(0.004)\end{array}$ & $\begin{array}{l}0.248 * * * \\
(0.013)\end{array}$ & $\begin{array}{l}0.006 * * * \\
(0.002)\end{array}$ & $\begin{array}{l}0.187 * * * \\
(0.006)\end{array}$ & $\begin{array}{l}7.957 * * * \\
(0.120)\end{array}$ & $\begin{array}{l}1.101 * * * \\
(0.043)\end{array}$ \\
\hline Month fixed effect & YES & YES & YES & YES & YES & YES & YES & YES & YES \\
\hline Year fixed effect & YES & YES & YES & YES & YES & YES & YES & YES & YES \\
\hline Prefecture fixed effect & YES & YES & YES & YES & YES & YES & YES & YES & YES \\
\hline Observations & 3,807 & 3,807 & 3,807 & 3,807 & 3,807 & 3,807 & 3,807 & 3,807 & 3,807 \\
\hline $\mathrm{R}$-squared & 0.21 & 0.77 & 0.17 & 0.22 & 0.46 & 0.04 & 0.37 & 0.77 & 0.35 \\
\hline
\end{tabular}

Note: Standard errors are given in parentheses; *,**, and *** indicate statistical significance at the 10,5 , and 1 percent levels, respectively. 
Table 3: Effects of climate factors on monthly suicide rates using the prefecture fixed-effect model

\begin{tabular}{lccc}
\hline & $\begin{array}{c}\text { Total } \\
\text { suicide rate }\end{array}$ & $\begin{array}{c}\text { Male } \\
\text { suicide rate }\end{array}$ & $\begin{array}{c}\text { Female } \\
\text { suicide rate }\end{array}$ \\
& $(1)$ & $(2)$ & $(3)$ \\
\hline Average temperature (C) & $0.022^{* * *}$ & $0.030^{* * *}$ & $0.016^{* * *}$ \\
& $(0.002)$ & $(0.003)$ & $(0.002)$ \\
Total precipitation (100 mm) & 0.009 & 0.007 & $0.011^{*}$ \\
& $(0.006)$ & $(0.011)$ & $(0.006)$ \\
Constant & $2.081^{* * *}$ & $3.171^{* * *}$ & $1.051^{* * *}$ \\
& $(0.026)$ & $(0.045)$ & $(0.025)$ \\
Month fixed effect & YES & YES & YES \\
Year fixed effect & YES & YES & YES \\
Prefecture fixed effect & YES & YES & YES \\
& & & \\
\hline Observations & 3,807 & 3,807 & 3,807 \\
R-squared & 0.37 & 0.32 & 0.13 \\
\hline
\end{tabular}

Note: Standard errors are given in parentheses; ${ }^{*}, * *$, and $* * *$ indicate statistical significance at the 10 ,

5 , and 1 percent levels, respectively. 
Table 4: Predicted impacts of climate change on crime and suicide

\begin{tabular}{lccccc}
\hline & $\begin{array}{c}\text { Mean annual } \\
\text { number between } \\
2009-2014\end{array}$ & \multicolumn{2}{c}{$\begin{array}{c}\text { Additional number in } \\
2100 \text { based on the } \\
\text { RCP2.6 scenario }\end{array}$} & $\begin{array}{c}\text { Additional number in } \\
\text { 2100 based on the } \\
\text { RCP8.5 scenario }\end{array}$ \\
& $(1)$ & \multicolumn{2}{c}{$(2)$} & $(3)$ \\
\hline Temperature & 15.5 & +1.1 & $(7.1)$ & +4.4 & $(28.4)$ \\
Murder & $1,039.3$ & +16.8 & $(1.6)$ & +67.1 & $(6.5)$ \\
Assault & $26,894.3$ & +251.5 & $(0.9)$ & $+1,005.8$ & $(3.7)$ \\
Sexual assault & $7,153.7$ & +117.3 & $(1.6)$ & +469.4 & $(6.6)$ \\
Robbery & $3,709.5$ & +16.8 & $(0.5)$ & +67.1 & $(1.8)$ \\
Burglary & $121,218.0$ & $+1,324.4$ & $(1.1)$ & $+5,297.4$ & $(4.4)$ \\
Vehicle theft & 22214.7 & +100.6 & $(0.5)$ & +402.3 & $(1.8)$ \\
Suicide & $28,184.2$ & +368.8 & $(1.3)$ & $+1,475.2$ & $(5.2)$ \\
\hline
\end{tabular}

Note: The numbers in columns 2 and 3 represent the total number of additional crimes and suicides that will occur because of climate change in 2100 relative to the number that would occur if the temperature remained at the 2009-2014 average. Numbers in parentheses are growth rates compared to the annual average between 2009 and 2014. 


\footnotetext{
${ }^{\mathrm{i}}$ We collected average atmospheric pressure data in hectopascals and average humidity from the Japan Meteorological Agency. However, they are not included in the regression model to avoid the correlation between average temperature and average total precipitation.

ii Although we used a non-linear estimation model to examine the relationship between climate and violent behavior, we found that the results of the non-linear model were virtually the same as the linear estimation results.

iii Although the results show that crime cases per 100,000 persons will increase due to the increase in the average temperature, it is difficult to conclude whether these increases are large compared to the predictions given in previous studies because each study uses different crime and climate data. For example, Jacob et al. (2007) computed crime rates by dividing the actual number of crimes during a week by the average number of weekly crimes within the jurisdiction; thus, their rates were different from the crime rates used in this study. In addition, Ranson (2014) used the maximum daily temperature for predictions rather than the average temperature.

iv As a robustness check, we created a regression model of the interaction terms between the average temperature and seasonal dummies. However, in most cases, the interaction terms are insignificant, while the average temperature results are virtually the same. These results indicate that the average temperature affects the crime and suicide cases in general.
} 